\title{
Protection Technology Of River Bends And Experimental Study On Its Effect Of Soil Erosion Control
}

\author{
Pengcheng $\mathrm{Li}^{1, \mathrm{a}}$, Xiuling Sun ${ }^{1, \mathrm{~b}^{*}}$,Xinghao Miao ${ }^{1, \mathrm{c}}$, Senyan $\mathrm{Li}^{2, \mathrm{~d}}$, \\ Jiarong Wang ${ }^{1, e}$,Yuemin Wang ${ }^{1, f}$ \\ 1School of Civil and Hydraulic Engineering, Shandong University, Jinan, China \\ 2Administration of Haihe River Basin Water Conservancy in Shandong Province, Jinan, China \\ a15866711875@163.com, bxiuling-sun@sdu.edu.cn, ${ }^{\mathrm{c}} 1320329010 @ q q . c o m$, \\ dlipengchengsdu@163.com, evjry12243@qq.com, ${ }^{\mathrm{f}} 443172363 @ q q . c o m$
}

Keywords: Tuhai River; River bends; Physical model; Slope protection; Soil Erosion Control

Abstract:To study the mechanism of anti erosion of river bend protection technology and research on the factors affecting erosion of slope protection, It selects typical river bend of the Shandong Haihe River Basin Tuhai River , and experiments on the ecological slope protection impact. It uses four different types of ecological slope protections as the experimental object to analyze the test data and compare the experimental phenomena. Experimental results show that: In different flow conditions, the slope erosion and scour seem basically consistent. Individually stake slope protection effect is poor. Stone-cage slope protection, spur-dike slope protection and the stake and grass protection firm the bottom of the slope obviously. The soil loss of spur-dike slope is the lowest, flow velocity between spur dikes decreases significantly and soil reinforcement increases more than $70 \%$ compared with spur-dike slope. The experiment provides technical support for Tuhai River bend slopes.

\section{Introduction}

With the rapid development of society and economy, although infrastructures of Chinese water conservancy projects have been gradually developing, we only pay attention to the construction of Engineering subjects and we ignore the slopes especially slope protection of river bends, thus causing soil and water loss and even the slope instability.It is also often seen blocking the river by the sediment deposition. All of these increase the difficulty of flood control and drainage.

Damages of river bend slopes are particularly serious to the river embankment. Its main types are(1)With time going on ,due to the design standards or constructions of the slope leading to its low stability, the slope creep causes the structure instability ,the partial and even whole collapse;(2)Although the stability of river bend slope is good, it leads to the shear strength reduction of soil slope because of the influence of water erosion, wind erosion and other external conditions, especially the infiltration, erosion, scour of the high-speed flow in river bends. And the phenomenon of the damage to the structure stability is widespread ${ }^{[1,2]}$.

In order to study the effect of different protection techniques of soil erosion in the river bends, the project team selects a narrow river bend with turbulent flow of Guanshi River, the branch of Tuhai River and chooses representative field soil in the test area for the experiment.It also uses four different types of slope protection to study on the effect of soil erosion control.

\section{Experiment design and scheme}

\section{Experiment design}

The prototype experiment area is selected from Guanshi River of Shandong Province, which is located in the section of Liulisi Town, Gaotang County, Liaocheng City. The selected river course is narrow and fast flowing, whose average flow rate reaches about $1.05 \mathrm{~m} / \mathrm{s}$. Both sides of the river slope are mainly composed of cohesive soil. The selection belongs to the temperate monsoon climate zone, where is hot and rainy in summer. Nearly $70 \%$ annual rainfall concentrates in summer, and it often results torrential rain and flood. In contrast, there is less precipitation in other seasons. 
The hydraulic test model sites in conservancy experiment building, Qianfoshan campus of Shandong University and the test soil is selected from representative field soil in Gaotang county , Shandong Province. The physical and chemical properties of the used soil are shown in table1.

Table 1. Physical and chemical properties of the used soil

\begin{tabular}{|c|c|c|c|c|c|c|c|c|c|c|}
\hline \multirow[b]{2}{*}{ Used soil } & \multicolumn{6}{|c|}{ Grain-size analysis results/\% } & \multirow[b]{2}{*}{$\begin{array}{c}\text { Organic content } \\
(\mathbf{g} / \mathrm{kg})\end{array}$} & \multirow[b]{2}{*}{ Density $\left(\mathbf{s} / \mathrm{m}^{2}\right)$} & \multirow[b]{2}{*}{$\mathrm{pH}$} & \multirow[b]{2}{*}{$C_{\mathrm{u}}$} \\
\hline & $>1 \min$ & $\underset{\min }{1 \sim 0.05}$ & $0.05 \sim 0.01 \mathrm{~mm}$ & $0.01 \sim 0.005 \mathrm{~mm}$ & $0.005 \sim 0.001 \mathrm{~mm}$ & $<0.001 \mathrm{~mm}$ & & & & \\
\hline Cohesive soil & 0 & 52.36 & 19.63 & 8. 36 & 15. 32 & 4. 33 & 6. 12 & 1. 51 & 6.1 & 17.50 \\
\hline
\end{tabular}

This model includes control section in the upstream and test section in the downstream .We take some measures to form a certain velocity of flow required in the test.The downstream river model is constructed according to the selected river, where the detector is set to intercept the dirt. The downstream slope of the test section is smooth with longitudinal gradient of 1:50 and the bending 30 degrees arranged in the upper and lower sections. We use the distorted model whose actual length and it of the channel model is 1:1.The length of upstream and downstream are $6 \mathrm{~m}$ and $9 \mathrm{~m}$ respectively.It's actual width and it of the channel model is $2.8: 1$, the maximum width of the transition section is $1.4 \mathrm{~m}$ and the width of downstream is $0.9 \mathrm{~m}$.It uses the gradient of the protection structure 1:3 and the soil fixing device and geotextiles are set on on both sides of the slope.To prevent the slope deformation and play a certain role to prevent water penetration excessively,the degree of compaction of both slopes and the bottom slope soil of the river must be more than $90 \%$. And then measure and record velocities of flow,soil erosion etc of the river bends in different ecological slope protection scheme. The specific is as shown in fig. 1 .

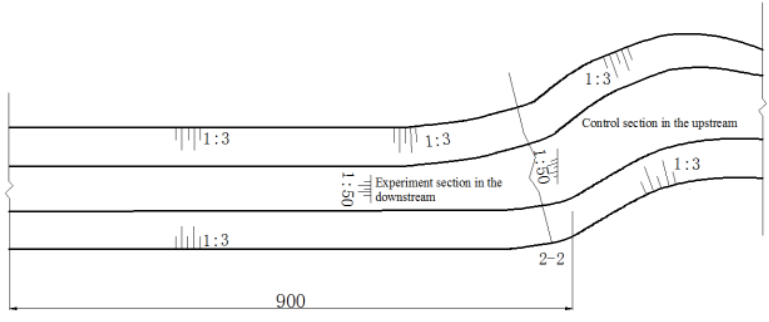

Fig.1 River model plan of the experiments

\section{Experiment scheme}

Slope protections of river bends used in the experiment and their specific requirements:a.without any protection;b.stake slope protection :According to the design size,the materials used to make stakes should be less scars and without corrosion and hollow . Compared with the big,the diameter of the small has little difference. And the bark of the tree must be stripped before making stakes ,the stakes are fixed in the distance of $5 \mathrm{~cm}$ in the bottom of the slope.c.grass slope protection:A certain density of vegetation is planted on the slope and then put them under maintenance to meet the experiment requirements. d.the stake and grass slope protection:The grass and wood comprehensive protection is the combination of the above two types e.stone-cage slope protection:The low carbon steel wire with ductility, high strength and high resistance to corrosion is woven into cages shaped like boxes and then add a certain range size of stones in the cages to make the gabions. In a certain density reasonably layout them in the slope bottom to form the gabion retaining wall.f: The spur-dike slope protection is designed in oblique head type, and according to the actual situation of the river bend it layouts the spur-dike dam on the river bank slope with reasonable density.

Firstly it completes the layout of the river slope protection structure, and then turns on the pump.The water flows to the channel, with the velocity increasing from 0 to $1.05 \mathrm{~m} / \mathrm{s}$ gradually, furthermore it keeps the opening degree of water pump unchanged and each runoff process of the experiment lasting for $20 \mathrm{~min}$.In the process of drainage, when the slope erosion begins we records the flow velocities of the initial, terminal and the middle of the experiment section at the bottom of the slope every minute, and we takes the average as the average flow velocities of the slope bottom. At the end of the experiment, we sample the soil where is $10 \mathrm{~cm}$ to the slope 
bottom in the test section and we measure its water content, vertical penetration depth and estimate the weight of the erosion and scour soil.

\section{Experiments results and analysis}

\section{Analysis of test point velocity of slope experiment in the initial and terminal section}
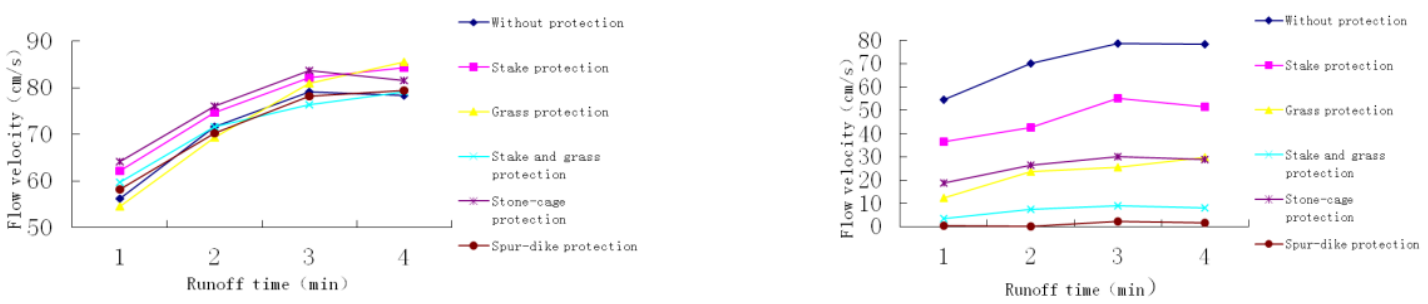

Fig.2 Flow velocitiy of the initial trial position versus time Fi.3 Flow velocitiy of the terminal rial position versus time

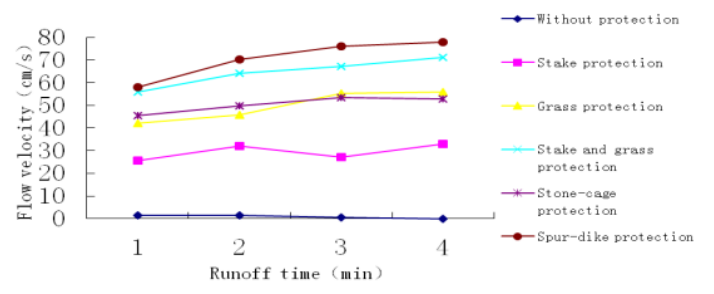

Fig.4 Difference of the beginning to end velocity of flow versus time

Runoff erosion is carried out in the experiment for six times .Variation curve of the velocities of the initial experiment area with different slope protection is as shown in figure 2 and flow velocities of each stage are basically the same.This shows that the initial conditions of each experiment are basically the same and each experiment is comparable.The impact resistances of natural rivers include frictional resistances and partial resistances and the partial resistances include the bed resistance of the bottom and the resistance of the river bank and the side wall ${ }^{[3]}$, and the increase of side resistance can effectively reduce the flow velocity thus reducing the scouring flow of the river bank. The flow velocity has a certain decline in the slope bottom of the terminal experiment position in spite of the one without protective measures. Therefore, strengthening the slope protection device effectively enhances the protection of the slope and reduces the soil erosion.

Compared to others,the slope with stake and grass protection and the one with spur-dike protection greatly reduce the flow velocity and the effect of reducing the soil erosion is efficient. Among them the slope with stake and grass protection can produce countless small eddy current in the grass of the slope bottom, reduce energy, and effectively control the soil erosion and surface runoff. When the flow velocity stays stable, in the period $15 \mathrm{~min}-20 \mathrm{~min}$ of the experiment the average velocity reduces from $77.825 \mathrm{~cm} / \mathrm{s}$ to $8.62 \mathrm{~cm} / \mathrm{s}$ with a decline of $803 \%$. The spur-dike protection can prevent the river banks from direct erosion to avoid digging and brushing the slope. At $20 \mathrm{~min}$ in the initial experiment position the flow velocity is $79.46 \mathrm{~cm} / \mathrm{s}$, and it reduces to $1.68 \mathrm{~cm} / \mathrm{s}$ (close to 0 ) at the fifth spur with a considerable decline.

\section{The soil permeability analysis of the same slope position in the end of the experiment.}

Before and after the soil erosion control experiment of the river model, it takes the soil samples where is $10 \mathrm{~cm}$ to the slope edge and measure moisture content. The experiment results are shown in table 2 . The experiment without protective measures leads to serious erosion and scour in the slope bottom, so the measured data does not have reference. There are $8.78 \%$ and $7.93 \%$ increases in the stake protection slope and stone-cage protection slope respectively,and the soil moisture changes greatly. There is only a increase of $5.41 \%$ in the stake and grass protection slope with little change of moisture content.It indicates that ecological 
slope protection can effectively prevent water penetration and the weathering and disintegration because of the high speed flow at the river bend.

\begin{tabular}{ccc}
\multicolumn{3}{c}{ Table2 Soil moisture and penetration depth of the slope } \\
\hline Protection types & $\begin{array}{c}\text { Increased rate of } \\
\text { measured } \\
\text { soil water content }\end{array}$ & $\begin{array}{c}\text { penetration depth }(\mathrm{cm}) \\
\text { Without protection }\end{array}$ \\
Stake protection & - & - \\
Grass protection & 5.78 & 17.10 \\
Stake and grass & 5.86 & 14.62 \\
Stone-cage protection & 5.41 & 13.21 \\
Spur-dike protection & 7.93 & 16.95 \\
\hline
\end{tabular}

* Note:the flow velocity increases from the 0 uniformto $1.05 \mathrm{~m} / \mathrm{s}$ in uniform speed within $15 \mathrm{~min}$ and the experiment continues for $20 \mathrm{~min}$.

The penetration depth of water also has a great impact on the slope stability, and the measured data and the changes of moisture content have the same rules. Therefore the stakes and grass protection is the better slope protection in this experiment conditions .

\section{Soil erosion of different protection slopes}

For the slope without protection measures, when the flow velocity is small,there are partial scour at the bottom of the experiment slope section in the river bend and the brush seems serious, the bank slope is in an unstable state.With the flow velocity increasing gradually, the water depth gets bigger and there exist transverse circulations in the flow of river bends.Because of shear stress and centrifugal force of the water flow, there are serious scour and erosion in more than $60 \%$ of experiment section and the slope is in a very unstable state with obvious collapse. The scoured soil is to be different with different protections and the experiment data is shown in table 3 .

\begin{tabular}{c|c}
\multicolumn{2}{c}{ Table3 The scoured soil of different slope protection } \\
\hline Protection types & Weight of the scoured soil $(\mathrm{kg})$ \\
\hline Without protection & 6.21 \\
Stake protection & 5.235 \\
Grass protection & 0.962 \\
Stake and grass protection & 0.72 \\
Stone-cage protection & 0.575 \\
Spur-dike protection & 0.556 \\
\hline
\end{tabular}

* Note: the experiment conditions are the same as in table 2.

From the change of soil erosion, it can easily conclude that the effect of stake protection is not obvious because of compaction of used soil and bond strength of the soil with stakes and the reduced weight is only $0.975 \mathrm{~kg}$ compared with the condition without protection. The effect to reduce the soil loss is more obvious with stone-cage protection or spur-dike protection and the loss of the scoured soil is $0.575 \mathrm{~kg}, 0.556 \mathrm{~kg}$ respectively.But the stone-cage protection is not a better choice considering the ecological environment,the maintenance of river profile and preservation of the aquatic biodiversity. With the special structure,spur-dike slope protection has damage to the original river bend and considering the high cost,high construction difficulty and the effect to the velocity of the center flow, it needs further research for implementing the scheme in engineering. The loss of the scoured soil is $0.72 \mathrm{~kg}$ with the stake and grass protection, which is $0.145 \mathrm{~kg}$ and $0.164 \mathrm{~kg}$ more than the stone-cage protection and spur-dike protection respectively,and it proves to be a better slope protection considering the ecological effect. 


\section{Conclusions}

From the simulation experiment of soil fixation and scour prevention based on the river model originated from Guanshi River, tributary of Tuhai River, it gets the measured data and the comparison of river profile before and after the slope erosion. The preliminary conclusions are as follows:

(1)For bends with larger curvature ,velocity or water depth,stone cage protection used in overall slope can effectively reduce the flow rate and firm the slope without considering construction cost.For bends with smaller curvature, velocity or water depth,it can use the grass protection or stake and grass protection considering the specific circumstances, meanwhile the stake and grass slope protection contributes more to the ecology,environment and aquatic biodiversity.

(2)The spur-dike protection can maintain the stability of the slope and dissipate the energy,so it is very valuable slope protection measures. Considering its special structure, the construction cost and its influence to the river velocity,the implemented scheme needs further study in engineering.

(3)It can use the efficient slope protection according to the measured data and statistics when it comes to the actual slopes with different soil types.For the slope with cohesive soil it can use grass protection or the stake and grass protection to effectively reduce the soil erosion because of the high speed flow.For the slope with cohesionless soil, it should pay special attention to the soil erosion .It should not use the stake protection and grass protection and stone-cage protection is the appropriate protective measures.

(4)For the slope of different types and different geology, it can use more efficient scheme according to the experiment results and the specific situation and it can also be further demonstrated.

\section{Acknowledgment}

This work was supported by a grant from The Major Program of Water Conservancy Scientific Research of Shandong (No.SDSLKY201207).

\section{References}

[1]Zhigang Li, Yunhe Chen,Guochao Qian.Field Erosion Simulation Test Study For Expressway Slopes [J]Journal Of Highway And Transportation Research And Development,2004,21(1): 30-32

[2]Liping Zhang, Keli Tang,Pingcang Zhang , etal. Experiments of artificial simulation rainfall and setting water intiating accumulated material in debris flow origin phce $[\mathrm{J}]$. Journal 0fMountain Science, 1999, 17(1): $45-49$.

[3]Bin Luo, Houtian Hu, Xiaoping Lu. Study on cutting slope surface erosion of granite duvium in the south of china[J]. JotLmal of Railway Engineering Society, 1999(3): 82-85.

[4]Jianping Yuan,Dinsheng Jiang, Miaoxia Wen.Research on rainfall penetration testing device of slopeland[J]. Bulletin of Soil and Water Conservation, 1999, 19(1): 24-27.

[5]OGUNLELAAO, MAKANJUIAMB. Hydraulic roughness of some African grasses [J]. Agric Engng Res, 2000, 75: 221-224.

[6]JAMESCS , BIRKHEADAL . Flow resisutllce of emergent vegetation[J]. Journal of Hydraulic Research, 2004, 42(4): 390-398.

[7] Xian-tuo Wang, Yu-kuan Wang, Fubin, etal. Experimental Study on Runoff Characteristics of Slope Land in Sichuan Basin [ J ]. Journal of Soil andWater Conservation, 2006, 20 ( 5 ) :9 - 12. 
[8] Wan-zhong Wang, Ju-ying Jiao. The Rainfall Erosion and Sediment Yieldand Sand Transport of Loess Plateau[ M]. Beijing: Science Press, 1996.

[9] Ke-li Tang. Water and Soil Conservation in China[M]. Beijing: Science Press, 2003. 